\title{
Erratum
}

Due to a printing error, the contents listing for the previous issue, Volume 44, Number 1, September 1995, was printed incompletely. The complete contents listing prints below.

\section{Pastoral Psychology}

Volume 44, Number 1

September 1995

\section{CONTENTS}

Conversion Dreams

Kelly Bulkeley

Reflections on the Holocaust

David Glick

The Availability and Importance of Denominational Support

Services as Perceived by Clergy Husbands and Their Wives

Michael Lane Morris and Priscilla White Blanton

The Will to be Known: Toward a Pastoral Anthropology of the Self

Frank Milstead Woggon 